\title{
Towards a multiphysics modelling framework for thermosensitive liposomal drug delivery to solid tumour combined with focused ultrasound hyperthermia
}

\author{
Wenbo Zhan ${ }^{1}$, Wladyslaw Gedroyc ${ }^{2}$, Xiao Yun $\mathrm{Xu}^{1}$ 四 \\ ${ }^{1}$ Department of Chemical Engineering, South Kensington Campus, London SW7 2AZ, UK \\ 2 Department of Radiology, Imperial College Healthcare NHS Trust, St Mary's Hospital, Imperial College London, \\ London, UK
}

Received: 1 August 2018 / Accepted: 31 October 2018 / Published online: 5 March 2019

\section{Graphical abstract}

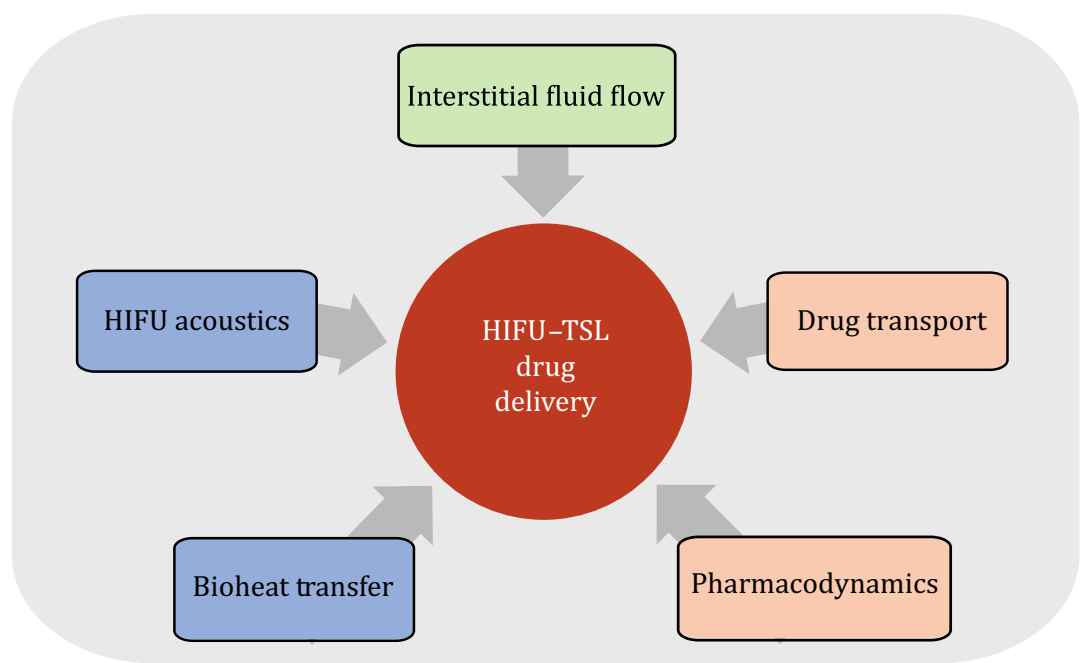

\begin{abstract}
Systemic toxicity and insufficient drug accumulation at the tumour site are main barriers in chemotherapy. Thermosensitive liposomes (TSL) combined with high intensity focused ultrasound (HIFU) has emerged as a potential solution to overcome these barriers through targeted drug delivery and localised release. Owing to the multiple physical and biochemical processes involved in this combination therapy, mathematical modelling becomes an indispensable tool for detailed analysis of the transport processes and prediction of tumour drug uptake. To this end, a multiphysics model has been developed to simulate the transport of chemotherapy drugs delivered through a combined HIFU-TSL system. All key delivery processes are considered in the model; these include interstitial fluid flow, HIFU acoustics, bioheat transfer, drug release and transport, as well as tumour drug uptake. The capability of the model is demonstrated through its application to a 2-D prostate tumour model reconstructed from magnetic resonance images. Our results not only demonstrate the feasibility of the model to simulate this combination therapy, but also confirm the advantage of HIFU-TSL drug delivery system with enhancement of drug accumulation in tumour regions and reduction of drug availability in normal tissue. This multiphysics modelling framework can serve as a useful tool to assist in the design of HIFU-TSL drug delivery systems and treatment regimen for improved anticancer efficacy.
\end{abstract}

$\bowtie$ Correspondence: yun.xu@imperial.ac.uk (X. Y. Xu) 
Keywords Chemotherapy, Drug delivery, High intensity focused ultrasound, Mathematical model, Thermosensitive liposome

\section{INTRODUCTION}

Numerous anticancer drugs have been developed with significant cytotoxicity observed in preclinical studies, but their clinical applications are limited for various reasons. Among these poor treatment efficacy and systemic toxicity are the main obstacles for effective chemotherapy in patients. This is largely attributed to insufficient drug penetration from microvasculature into tumour interior (Jain 1987a), resulting in inadequate drug accumulation for effective tumour cell killing. On the other hand, undesirable drug deposition in normal tissue may damage healthy cells so as to cause various side effects.

Thermosensitive liposome (TSL) combined with high intensity focused ultrasound (HIFU) offers a promising drug delivery system to overcome the limitations of conventional chemotherapy through actively targeted and triggered release of drugs at the tumour site. With this delivery system, drug-loaded TSL are intravenously administrated and then circulate with bloodstream to reach the tumour site. For well-designed TSL that are stable in blood, encapsulated drugs cannot be released at normal physiological temperature, and mild hyperthermia is required to trigger the release of the encapsulated contents (Gaber et al. 1995; Lindner et al. 2004; Tagami et al. 2011). Localised heating can be achieved by HIFU, which is favoured for its non-invasive nature and accuracy in clinical thermal therapy (Hynynen 2011). The safety and feasibility of the combined HIFU-TSL system have been reported in a very recent clinical trial, demonstrating enhanced intratumoural drug delivery for targeted treatment of liver tumours (Lyon et al. 2018). However, there is still a lack of understanding on the drug transport mechanism and tumour drug uptake in response to temperature variation upon HIFU heating.

Given the multiple steps involved in heat transfer and drug transport and the complex interplays among tumour, TSL and anticancer drugs, mathematical modelling plays an increasingly important role in gaining a deep understanding of drug delivery systems and predicting their treatment efficacy. Early mathematical models (Baxter and Jain 1989, 1990, 1991) were developed to study the transport of interstitial fluid and macromolecules in solid tumour. These were subsequently extended to multiple scales for examining the effects of different factors on drug delivery (Eikenberry
2009; El-Kareh and Secomb 2000; Goh et al. 2001; Liu et al. 2013; Luu and Uchizono 2005; Teo et al. 2005; Zhao et al. 2007). Results based on a 1-D drug transport model demonstrated the importance of blood temperature in determining the overall delivery outcome using TSL (El-Kareh and Secomb 2003). The performance of TSL was further compared to conventional chemotherapy and stealth liposomes under different conditions (Gasselhuber et al. 2012a), whilst a systematic parametric study was performed to identify the most influential factors in determining the peak intracellular concentration using a TSL-HIFU system (Liu and $\mathrm{Xu}$ 2015). The drug distribution in a 2-D idealised tumour geometry via TSL-mediated delivery was examined using a transport model that ignored the effect of convection (Zhang et al. 2009). Although a bioheat transfer model and macroscopic transport model were integrated in a pioneer study to simulate TSL drug delivery under different heating schedules (Gasselhuber et al. 2012b), existing spatially resolved drug transport models do not include HIFU acoustics and temperature-dependent tumour and drug properties.

The aim of the present study is to develop a multiphysics model for TSL-mediated drug delivery combined with HIFU heating. This requires integration and coupling of models for HIFU acoustic field, tissue and blood temperature, interstitial fluid flow, TSL and drug transport/reaction and tumour drug uptake. The integrated model has been applied to real tumour geometry reconstructed from patient-specific images. Heat-induced variations in transport properties of the drug and tumour are considered, which are temporally and spatially dependent. Anticancer efficacy is evaluated based on the percentage of survival tumour cells by solving the pharmacodynamics equation using the predicted intracellular drug concentration.

\section{RESULTS}

A total dose of $50 \mathrm{mg} / \mathrm{m}^{2}$ (Gabizon et al. 1994) TSL doxorubicin is intravenously administrated (Gasselhuber et al. 2012b) at the beginning of the treatment for a $70 \mathrm{~kg}$ patient, with HIFU heating being applied simultaneously (Liu and Xu 2015) over a period of $60 \mathrm{~min}$ (Grüll and Langereis 2012). The two focus regions are 
heated sequentially during the treatment, and sonication duration for each region is $1.0 \mathrm{~s}$.

\section{Interstitial fluid flow}

Drug transport and accumulation strongly depend on the interstitial fluid field in the tumour and surrounding normal tissue. This is because drug migration by convection is determined by the interstitial fluid velocity (IFV), while pressure gradient across the vessel wall directly influences the transvascular exchange of fluid and drugs. The predicted spatial distribution of interstitial fluid pressure (IFP) corresponding to a vascular pressure of $2080 \mathrm{~Pa}$ (Baxter and Jain 1989) is shown in Fig. 1, where uniform IFP distributions can be found in both the tumour and normal tissue. As higher IFP is observed in the tumour (1534 Pa) than in the normal tissue $(40 \mathrm{~Pa})$, pressure-induced convection of interstitial fluid mainly occurs within a thin layer at the interface between the two regions, where there is a large IFP gradient. The predicated IFP is found to be well within the range reported in experiment studies (Raghunathan et al. 2010).

High IFP in tumour is largely attributed to the leaky vasculature and dysfunctional lymphatics. It has been reported that large pores on tumour vasculature could increase the wall hydraulic conductivity by 10 -fold compared to normal blood vessels (Baxter and Jain 1989), making fluid exchange across the vessel wall much easier. Additionally, the lack of functional lymphatic vessels results in less fluid being drained out of the extracellular space, causing the build-up of IFP in the tumour.

\section{HIFU acoustic field}

Figure 2 shows that the spatial distribution of acoustic pressure is non-uniform, with the highest value of 1.98 MPa achieved at the focal centres. Outside the focus regions, acoustic pressure falls sharply to nearly zero. Figure 3 further reveals that there are several acoustic pressure peaks along the major and minor axis of the focus region. With the highest peak being at the centre, acoustic pressure attenuates rapidly towards the periphery, limiting the high power to a narrow region of $17.5 \mathrm{~mm}$ and $3.0 \mathrm{~mm}$ along the major and minor axis of the focus region, respectively.

\section{Temperature distribution in tissue and blood}

Variations of temperature over time with 60-min HIFU heating are represented in Fig. 4, which shows that temperatures in blood, tumour and normal tissues share

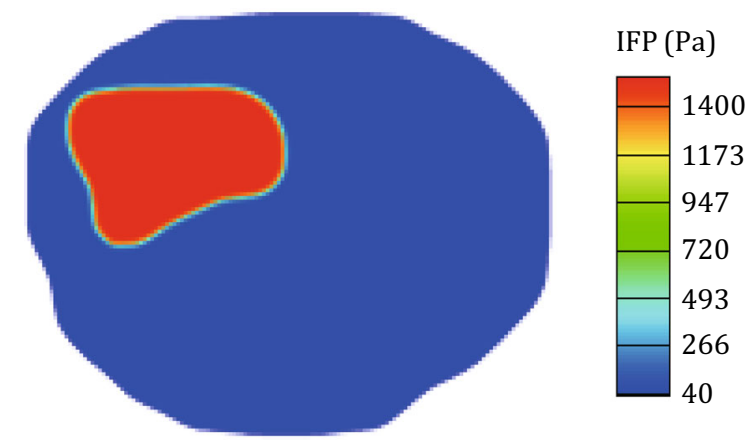

Fig. 1 Interstitial fluid pressure in tumour and surrounding normal tissue

a similar pattern in response to the heating schedule. The maximum tumour temperature reaches the target value of $42{ }^{\circ} \mathrm{C}$ rapidly, and then maintains at this level while the temperature controller described by Eq. 1 is in action. This is followed by a fall in temperature when HIFU heating terminates. The lower blood temperature can be attributed to blood flow that is efficient to remove heat from the HIFU focus regions, and this forced convection via blood serves as the main mechanism of heat transfer in the tumour and its holding tissue. Results show that temperature falls back to the normal body temperature of $37^{\circ} \mathrm{C}$ within 20 min after the cessation of heating. Since the HIFU focus regions for direct heating are located inside the tumour as shown in Fig. 5, temperature in the tumour rises faster and is higher than in the surrounding normal tissue, whereas temperature elevation in normal tissue mainly depends on heat transfer from the tumour, which in turn causes heat loss hence reduction in tumour temperature. However, given that heat is constantly carried away by the circulating blood, blood temperature in the tumour region is always lower than the tumour temperature. As blood in the tumour region is directly heated by HIFU, its spatial-averaged temperature is higher than blood temperature in the normal tissue.

Spatial distribution of tissue temperature at $10 \mathrm{~min}$ after heating is shown in Fig. 6. The highest temperature is observed in the focus regions where the tumour is directly heated by HIFU. Temperature elevation in the surrounding region is a consequence of heat transfer by convection and conduction from the focus regions, therefore, temperature in normal tissue is lower than in the tumour. The large difference in spatial-mean temperature between the tumour and normal tissues is desirable for enhanced drug release in the tumour region, while minimising drug availability in normal tissues. 


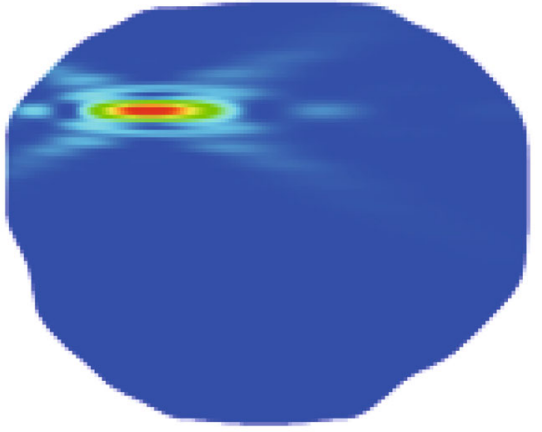

Focus region 1

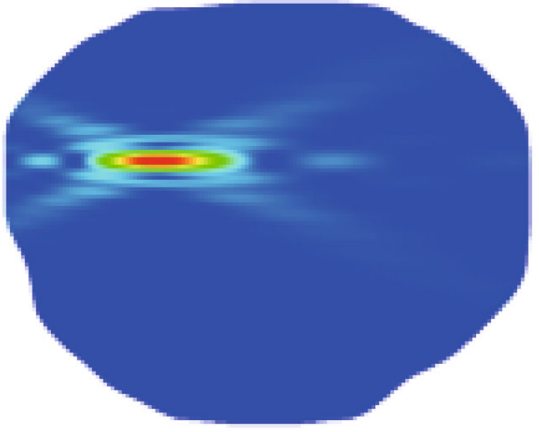

Focus region 2
Acoustic pressure

(MPa)

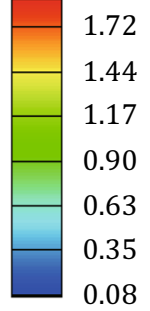

Fig. 2 Spatial distribution of acoustic pressure during the sonication period of each focus region
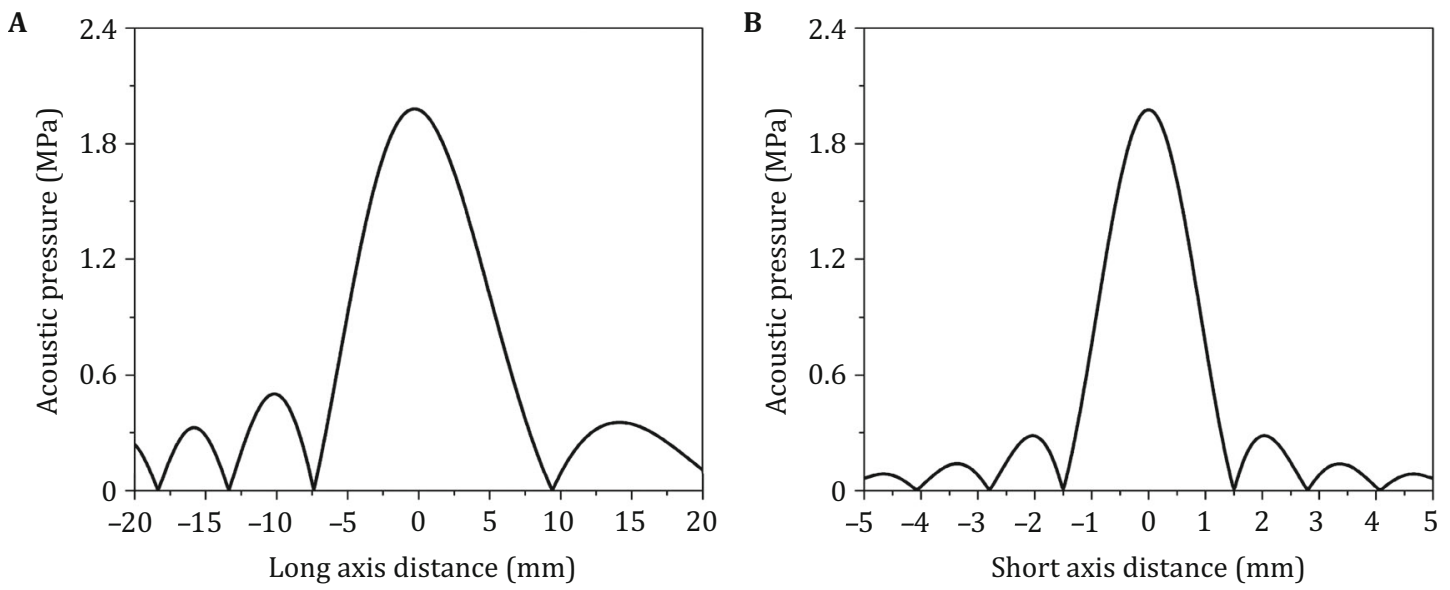

Fig. 3 Acoustic pressure variations in the focal plane along the major axis (A), and minor axis (B)
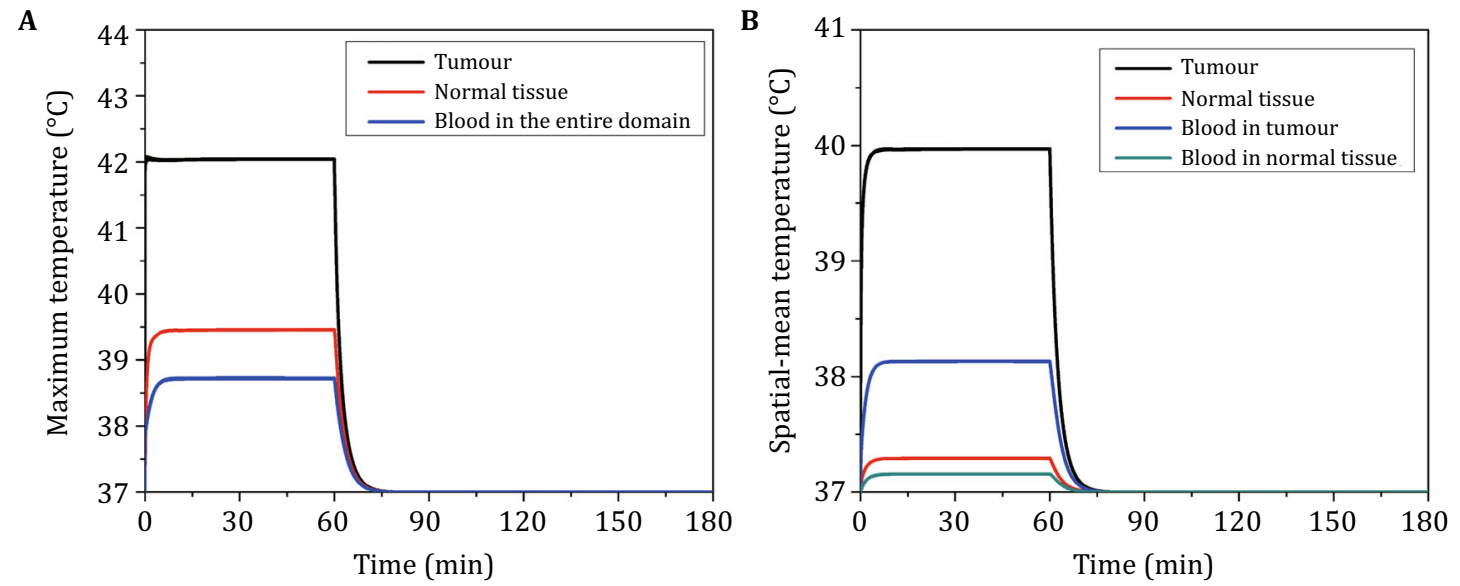

Fig. 4 Variations of temperature in tumour, blood and normal tissue as a function of time for 60 min heating. A Maximum temperature. B Spatial-mean temperature 

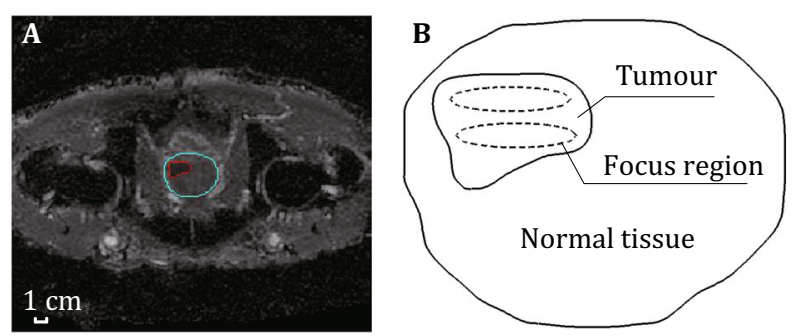

Fig. 5 Model geometry. A MR image of a prostate tumour (in red) and its surrounding tissue (in pule blue). B Reconstructed 2-D geometry and locations of two focus regions outlined by dash ellipses

\section{Drug transport}

Intravascular concentration of doxorubicin-loaded TSL in tumour and normal tissue are compared in Fig. 7A as a function of time. With bolus injection, intravascular TSL concentration reaches its peak at the very beginning of the treatment. It then falls continuously until it drops to zero due to rapid clearance in the circulatory system and enhanced release as temperature rises. Because the tumour temperature is approximately $2^{\circ}-$ $3^{\circ}$ higher than the normal tissue temperature during HIFU heating, TSL doxorubicin concentration reduces faster in the tumour than in normal tissue.

As shown in Fig. 7B, extracellular concentration of TSL doxorubicin in tumour starts to increase as soon as the treatment begins. This is owing to the high concentration gradient across the vasculature wall and enhanced vascular permeability in response to temperature rise. The concentration peaks at around $2 \mathrm{~min}$ after heating, and reduces progressively to zero as a result of enhanced drug release and reduced intravascular concentration as shown in Fig. 7A. Quantitative comparisons show that TSL doxorubicin concentration in normal tissues is at least three orders of magnitude less than in tumour, indicating that TSL doxorubicin mainly accumulate in the tumour with less efficient penetration into the surrounding normal tissue. This is more evident in Fig. 8 which shows the spatial distribution of TSL doxorubicin in the extracellular space at different time points. It is clear that the distribution of TSL doxorubicin is highly heterogeneous in the tumour upon HIFU heating. Tumour centre has lower concentration than in periphery as time proceeds, due to the fast doxorubicin release enhanced by HIFU heating within and around the focus regions. As the intravascular TSL doxorubicin concentration is reduced, the corresponding extracellular concentration decreases in the entire tumour and eventually become uniform.

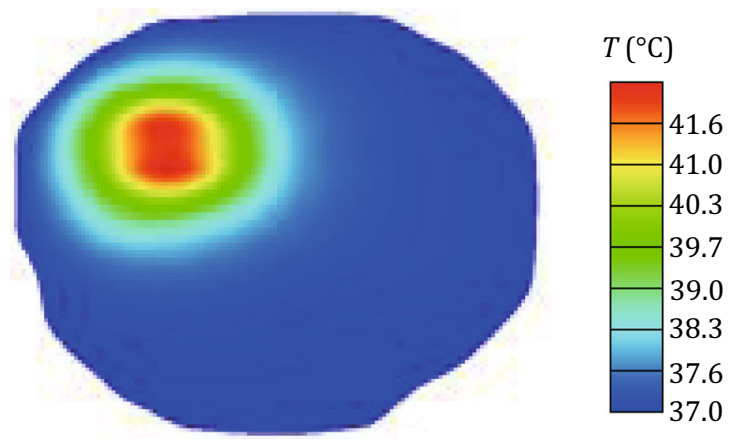

Fig. 6 Spatial distribution of tissue temperature at $10 \mathrm{~min}$ after heating

The time course of released doxorubicin concentration in blood and tumour extracellular space is given in Fig. 9. Doxorubicin is continuously released from TSL upon heating, resulting in a rapid increase in both intravascular and extracellular concentrations following drug administration. This is followed by a gradual fall of drug concentrations after reaching their peaks, owing to the reduction in intravascular concentration of TSL doxorubicin as time proceeds. Results also show that variation of free (bioavailable) doxorubicin concentration shares the same pattern with bound doxorubicin concentration, although the latter is two times higher in magnitude owing to the dynamic equilibrium as described by Eq. 1-4 and Eq. 1-6 in Table 1.

Figure 10 displays the spatial distribution of doxorubicin intratumoural concentrations and survival fraction of tumour cells at 10 min after administration. It is not surprising that doxorubicin intracellular accumulation is most efficient in tumour centre where HIFU focus regions are located, and it decreases radially towards tumour periphery with the lowest level at the left and bottom corners. As a consequence, the most effective cell killing occurs in the tumour centre, while drug uptake is less effective at the left and bottom corners which are the farthest from the focus regions. This non-uniform enhancement of drug uptake demonstrates the importance of the location of predesigned tumour regions.

\section{Tumour drug uptake}

Temporal profiles of intracellular drug concentration and cell survival fraction are represented in Fig. 11. The intracellular concentration rises to its peak at $1.15 \mathrm{~h}$ after TSL doxorubicin administration, and then gradually declines to zero. The treatment efficacy is evaluated in terms of dynamic cell density estimated by the pharmacodynamics model. Results show that the 


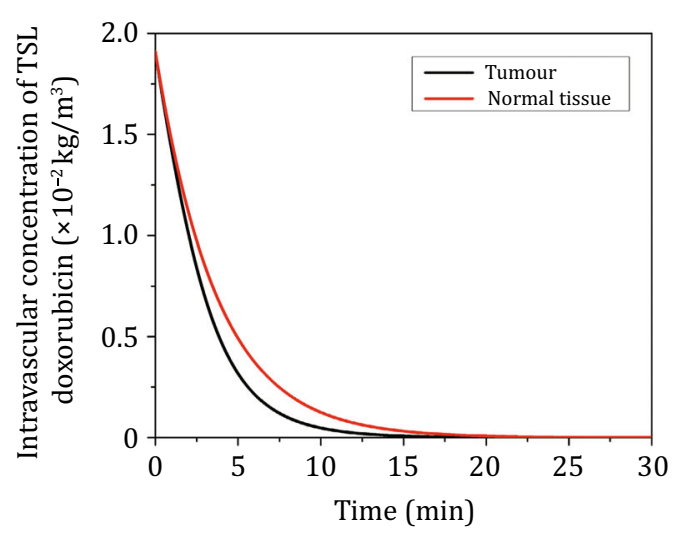

B

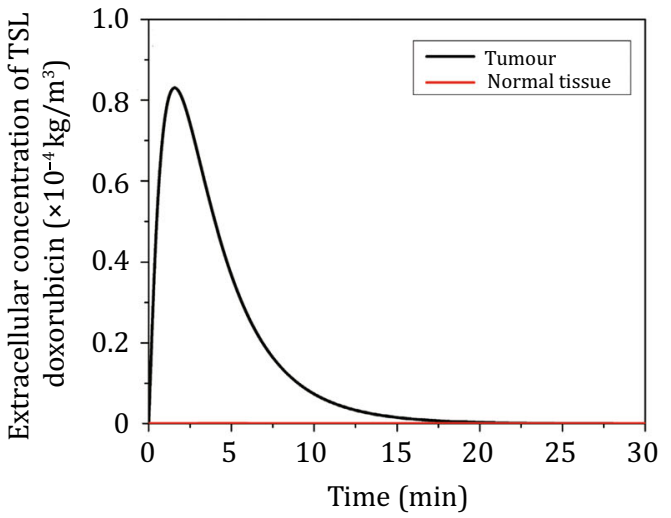

Fig. 7 Doxorubicin-loaded TSL concentrations in tumour and normal tissue as a function of time. A Concentration in bloodstream. B Concentration in extracellular space

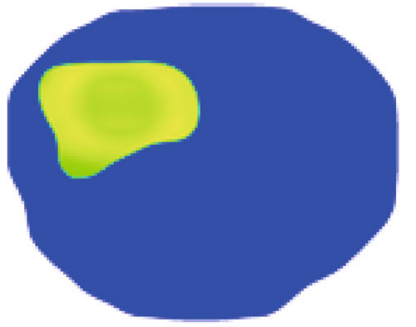

$1 \mathrm{~min}$

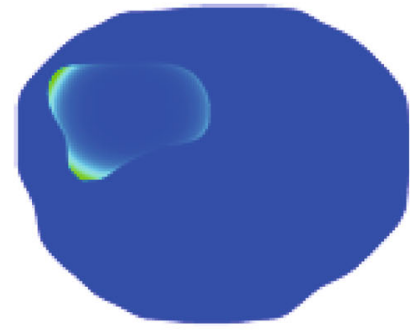

$10 \min$

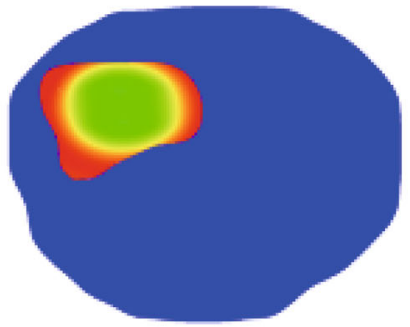

$2 \min$

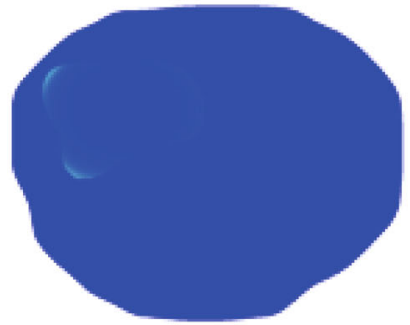

$15 \mathrm{~min}$

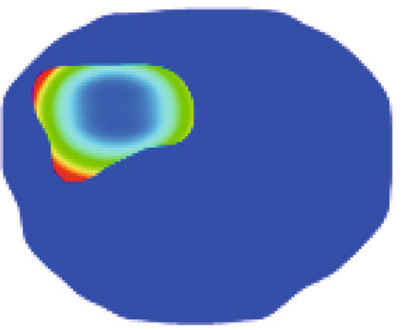

$5 \mathrm{~min}$

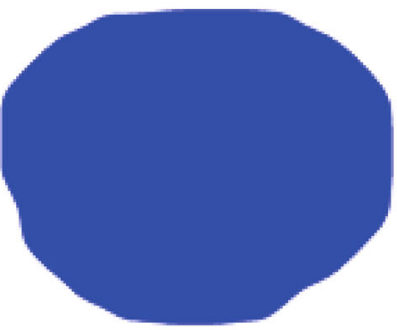

$30 \mathrm{~min}$
$C_{\mathrm{le}}\left(\mathrm{kg} / \mathrm{m}^{3}\right)$

$\square \begin{aligned} & 1.03 \times 10^{-4} \\ & 8.83 \times 10^{-5}\end{aligned}$

$7.36 \times 10^{-5}$

$5.88 \times 10^{-5}$

$4.42 \times 10^{-5}$

$2.95 \times 10^{-5}$

$1.48 \times 10^{-5}$

$5.00 \times 10^{-8}$

Fig. 8 Spatial distribution of extracellular concentration of TSL doxorubicin in tumour and surrounding normal tissue at various time points

survival rate of tumour cells starts to fall immediately after drug administration, but after $6 \mathrm{~h}$ cell killing rate slows down until at $8 \mathrm{~h}$ when drug-induced cell killing falls to zero and physiological degradation is overtaken by that of cell proliferation, causing the percentage of cell survival to increase gradually over time.

\section{DISCUSSION}

In this study, a multiphysics model is developed to predict the temporal and spatial profiles of temperature, drug concentrations and tumour cell survival for a TSL doxorubicin delivery system combined with HIFU. This integrated model is applied to a realistic prostate tumour geometry reconstructed from medical images. Our modelling results demonstrate the advantage of the combined HIFU-TSL therapy in achieving enhanced drug release at the targeted tumour site, while reducing drug availability in normal tissues. Simulations of HIFU heating reveals that when the acoustic power is focused at a preselected region, only the targeted region would experience sufficiently high temperature to trigger fast drug release. Since temperature in the normal tissue is 
A

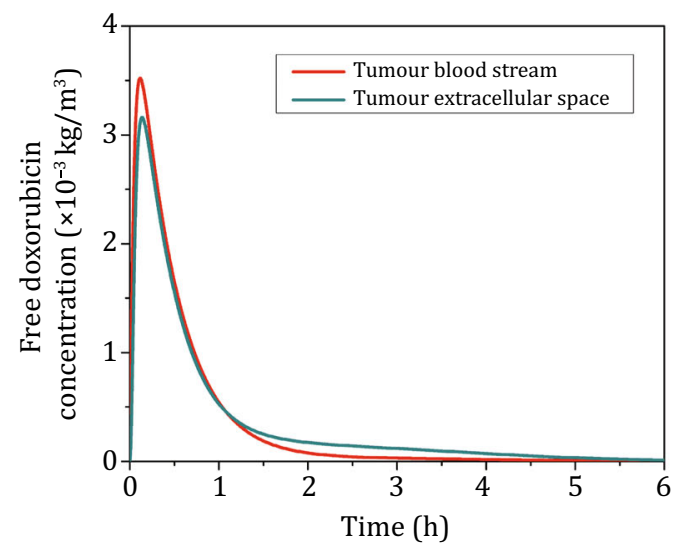

B

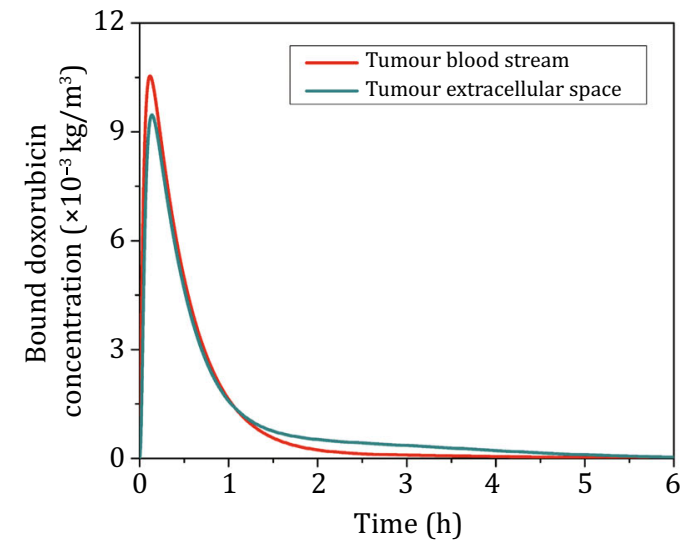

Fig. 9 The time course of doxorubicin concentration in tumour bloodstream and extracellular space. A Free doxorubicin. B Bound doxorubicin with proteins

Table 1 Governing equations for drug transport under TSL-mediated delivery

Pharmacokinetics model

$\frac{\mathrm{d} C_{\mathrm{lp}}}{\mathrm{d} t}=-C L_{\mathrm{lp}} C_{\mathrm{lp}}-k_{\mathrm{rel}} C_{\mathrm{lp}}$

Liposome encapsulated drug concentration in the interstitial fluid $\left(C_{\mathrm{le}}\right)$

$\frac{\partial C_{\mathrm{le}}}{\partial t}+\nabla \cdot\left(C_{\mathrm{le}} \boldsymbol{v}\right)=D_{\mathrm{l}} \nabla^{2} C_{\mathrm{le}}+F_{\mathrm{v}}\left(1-\sigma_{\mathrm{l}}\right) C_{\mathrm{lp}}+P_{1} \frac{S}{V}\left(C_{\mathrm{lp}}-C_{\mathrm{le}}\right) \frac{\mathrm{Pe}_{\mathrm{l}}}{\mathrm{e}^{\mathrm{P}_{\mathrm{l}}}-1}-F_{\mathrm{ly}} C_{\mathrm{le}}-k_{\mathrm{rel}} C_{\mathrm{le}}, \mathrm{Pe}_{\mathrm{l}}=\frac{F_{v}\left(1-\sigma_{l}\right)}{P_{\mathrm{l}} \frac{S}{V}}$

Free doxorubicin concentration in blood plasma $\left(C_{\mathrm{fp}}\right)^{*}$

$\frac{\partial C_{\mathrm{fp}}}{\partial t}=k_{\mathrm{rel}} C_{\mathrm{lp}}-\frac{V_{\mathrm{T}}}{V_{\mathrm{B}}}\left[F_{\mathrm{v}}\left(1-\sigma_{\mathrm{f}}\right) C_{\mathrm{fp}}+P_{\mathrm{fe}} \frac{S}{V}\left(C_{\mathrm{fp}}-C_{\mathrm{fe}}\right) \frac{\mathrm{Pe}_{\mathrm{f}}}{\mathrm{e}^{\mathrm{Pe}_{\mathrm{f}}}-1}\right]-C L_{\mathrm{fp}} C_{\mathrm{fp}}-\left(k_{\mathrm{a}} C_{\mathrm{fp}}-k_{\mathrm{d}} C_{\mathrm{bp}}\right)$

Bound doxorubicin concentration in blood plasma $\left(C_{\mathrm{bp}}\right)^{*}$

$\frac{\partial C_{\mathrm{bp}}}{\partial t}=\left(k_{\mathrm{a}} C_{\mathrm{fp}}-k_{\mathrm{d}} C_{\mathrm{bp}}\right)-\frac{V_{\mathrm{T}}}{V_{\mathrm{B}}}\left[F_{\mathrm{v}}\left(1-\sigma_{\mathrm{b}}\right) C_{\mathrm{bp}}+P_{\mathrm{be}} \frac{S}{V}\left(C_{\mathrm{bp}}-C_{\mathrm{be}}\right) \frac{\mathrm{Pe}_{\mathrm{b}}}{\mathrm{e}^{\mathrm{P}} \mathrm{b}-1}\right]-C L_{\mathrm{bp}} C_{\mathrm{bp}}$

Free doxorubicin concentration in interstitial fluid $\left(C_{\mathrm{fe}}\right)^{*}$

$\frac{\partial C_{\mathrm{fe}}}{\partial t}+\nabla \cdot\left(C_{\mathrm{fe}} \boldsymbol{v}\right)=D_{\mathrm{fe}} \nabla^{2} C_{\mathrm{fe}}+F_{\mathrm{v}}\left(1-\sigma_{\mathrm{f}}\right) C_{\mathrm{fp}}+P_{\mathrm{fe}} \frac{S}{V}\left(C_{\mathrm{fp}}-C_{\mathrm{fe}}\right) \frac{\mathrm{Pe}_{\mathrm{f}}}{\mathrm{e}^{\mathrm{P} \mathrm{e}_{\mathrm{f}}-1}}-F_{\mathrm{ly}} C_{\mathrm{fe}}+k_{\mathrm{d}} C_{\mathrm{be}}-k_{\mathrm{a}} C_{\mathrm{fe}}+D_{\mathrm{c}} V_{\max }\left(\frac{C_{\mathrm{i}}}{C_{\mathrm{i}}+k_{\mathrm{i}}}-\frac{C_{\mathrm{fe}}}{C_{\mathrm{fe}}+k_{\mathrm{e}} \varphi}\right)+k_{\mathrm{rel}} C_{\mathrm{le}}$

Bound doxorubicin concentration in interstitial fluid $\left(C_{\mathrm{be}}\right)^{*}$

$\frac{\partial C_{\mathrm{be}}}{\partial t}+\nabla \cdot\left(C_{\mathrm{be}} \boldsymbol{v}\right)=D_{\mathrm{be}} \nabla^{2} C_{\mathrm{be}}+F_{\mathrm{v}}\left(1-\sigma_{\mathrm{b}}\right) C_{\mathrm{bp}}+P_{\mathrm{be}} \frac{S}{V}\left(C_{\mathrm{bp}}-C_{\mathrm{be}}\right) \frac{\mathrm{Pe}_{\mathrm{b}}}{\mathrm{e}^{\mathrm{P}} \mathrm{b}-1}-k_{\mathrm{d}} C_{\mathrm{be}}+k_{\mathrm{a}} C_{\mathrm{fe}}$

Intracellular doxorubicin concentration $\left(C_{\mathrm{i}}\right)$

$\frac{\partial C_{\mathrm{i}}}{\partial t}=V_{\max }\left(\frac{C_{\mathrm{fe}}}{C_{\mathrm{fe}}+k_{\mathrm{e}} \varphi}-\frac{C_{\mathrm{i}}}{C_{\mathrm{i}}+k_{\mathrm{i}}}\right)$

${ }^{*} \mathrm{Pe}_{\mathrm{f}}$ and $\mathrm{Pe}_{\mathrm{b}}$ are defined in the same way as $\mathrm{Pe}_{\mathrm{l}}$ in Eq. 1-2

below the hyperthermia requirement, majority of the encapsulated doxorubicin remains inside the liposomes. While the primary purpose of HIFU heating is to trigger drug release from TSL, transport properties of the drug and tumour tissue also vary in response to temperature elevation, leading to improved drug transport and uptake during hyperthermia.

Tumour drug distribution and uptake can be highly heterogeneous when a single-element transducer is used, as the coverage of its focus region is very limited. This would be a serious limitation for the treatment of large tumours. In order to achieve a uniform hyperthermia temperature distribution within a tumour, multi-element transducers have been used which can simultaneously generate multiple focus regions, allowing wider coverage of the targeted tumour. Careful design of HIFU scanning trajectory and focus region locations can help homogenise the temperature distribution, so as to achieve enhanced drug release in the entire tumour. Our results also show that incorporating a temperature controller is effective at maintaining the desired tumour temperature during HIFU heating. 


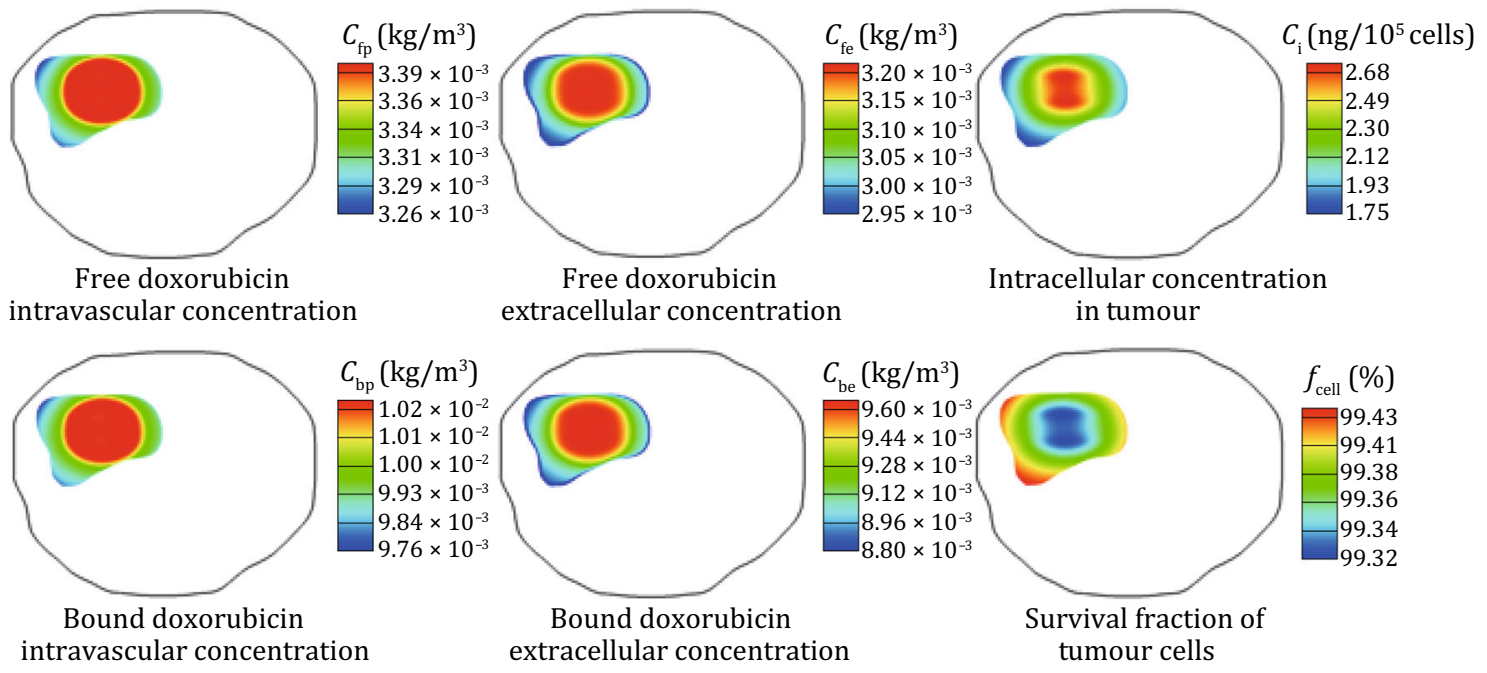

Fig. 10 Spatial distribution of doxorubicin concentration and cell survival fraction in tumour at 10 min after heating

A

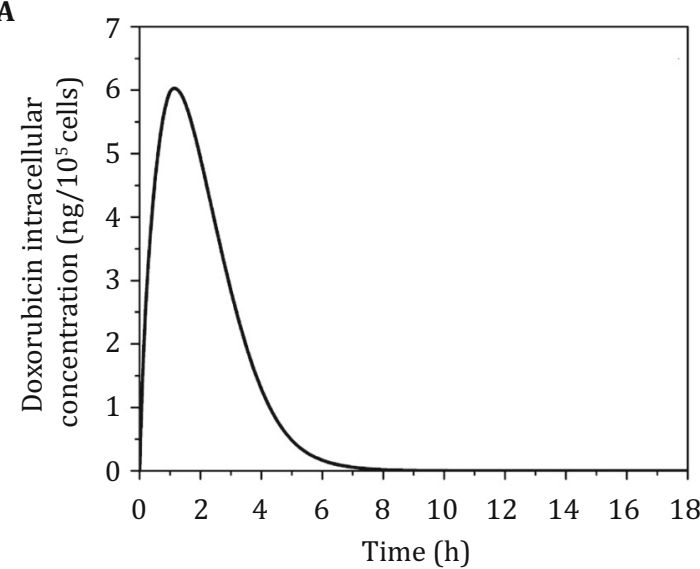

B

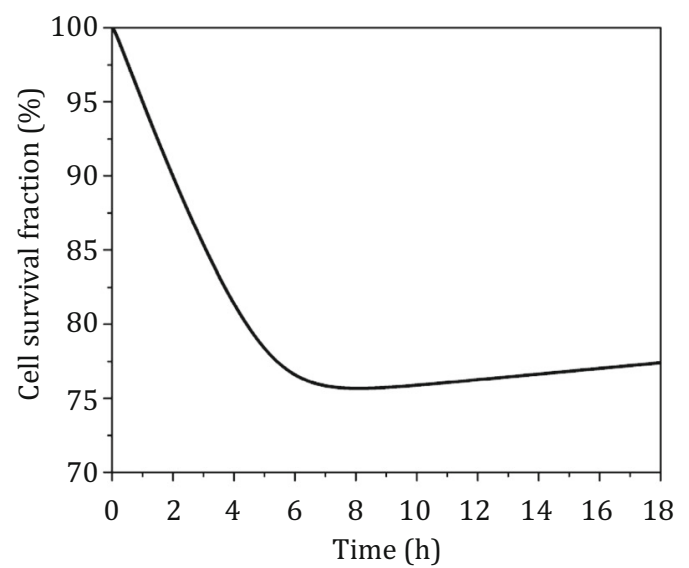

Fig. 11 The time course of intracellular concentration (A) and cell survival fraction (B) in the tumour under TSL-mediated delivery with HIFU heating

It is worth noting that TSL formulations can be unstable at body temperature in human blood (Hossann et al. 2010; Tagami et al. 2011, 2012). Ideal TSL should be able to release its payload upon hyperthermia only (Zou et al. 1993). However, this is difficult to achieve in vivo. Leaking at normal body temperature can lead to build-up of free doxorubicin in the circulatory system and normal tissue, increasing the risk of damage to normal cells and systemic side effects, such as cardiotoxicity (Cusack et al. 1993; Legha et al. 1982). Therefore, further improvements in TSL facilitated delivery combined with HIFU triggered release should aim to minimise drug leakage at body temperature, increase the release rate at the target temperature upon hyperthermia and optimise the heating schedule (Liu and $\mathrm{Xu}$ 2015). As a cost effective approach, mathematical modelling can facilitate comprehensive parametric analyses to identify the most influential factors and optimise their ranges, in order to provide guidance for the design of TSL and treatment regimen.

Our mathematical model was developed to describe the key interplays between solid tumour and HIFU-TSL drug delivery system. Although a 2-D model is used in this study for the sake of computational cost, the model can be applied directly to 3-D tumour geometry. Nevertheless, the present model involves a number of assumptions. First, physical complexities including cavitation and non-linear propagation of acoustic waves 
are ignored, but the effects of these complexities are expected to be minor for the conditions examined here (Sheu et al. 2011; Solovchuk et al. 2012). Second, the influence of temperature elevation on tumour properties is complex, and not all variations are included in the current model, such as change in interstitial fluid viscosity and temperature-dependent plasma clearance. Third, focus regions are ideally positioned in the tumour, without considering movement trajectory of ultrasound transducer, vasculature distribution and other microenvironment in tumour. Finally, there is a lack of experimental data for direct comparison and validation of our integrated model. Nevertheless, the adopted models have been validated separately by other researchers for HIFU acoustic field (Sheu et al. 2011) and HIFU-induced temperature variation (Staruch et al. 2011). The macroscopic transport model has been shown to be able to provide qualitative predictions on drug transport and accumulation in solid tumours (Bhandari et al. 2017; Zhan and Wang 2018). Given the complexities involved in the drug delivery process, more rigorous validation studies are needed in the future. Since averaged and representative values of model parameters are used in our simulations, the numerical results presented in this study are meant for qualitatively analysis rather than quantitative prediction.

\section{CONCLUSIONS}

A multiphysics model has been developed to examine the spatial distribution and temporal variation of TSL drug concentration, temperature upon HIFU heating and drug uptake for a combined HIFU-TSL doxorubicin delivery system. Our results demonstrate the capability of the model to simulate such a complex system, and indicate that this combined drug delivery system is able to achieve a localised treatment with enhanced drug delivery to tumour interior while keeping a relatively low level of drug concentration in normal tissue. The developed modelling framework can serve as a foundation for further comprehensive studies of TSL-mediated drug delivery with HIFU heating.

\section{METHODS}

\section{Mathematical model}

This modelling framework consists of several modules describing the different physical and biochemical processes involved in a HIFU-TSL drug delivery system. The relevant governing equations are summarised in Tables 1, 2, 3, 4 and 5 and their details are described below.

\section{Interstitial fluid flow}

The bulk movement of interstitial fluid in tissue extracellular space and the fluid exchange with systemic blood and lymphatic systems are crucial for drug transport in solid tumour. Given the size of a tumour is typically 2-3 orders of magnitude larger than the intercapillary distance, tumour and its surrounding normal tissue are treated as rigid porous media, with blood capillaries being represented as a uniformly distributed source term (Baxter and Jain 1989). Table 2 shows the continuity and momentum equations applied to describe the flow of incompressible Newtonian interstitial fluid in a porous medium.

\section{HIFU acoustic field}

Since acoustic energy radiated from a concave surface tends to be focused near the centre of curvature, such radiators have been used to produce localised heating in clinical applications. The effect of non-linear acoustic wave propagation on the heating of biological tissues by HIFU can be ignored if the applied focal intensity is within the range of $100-1000 \mathrm{~W} / \mathrm{cm}^{2}$ and the peak negative pressure in the range of 1-4 MPa (Sheu et al. 2011; Solovchuk et al. 2012). The acoustic field under the aforementioned conditions can be described by the fundamental equations (O'Neil 1949) given in Table 3.

\section{Bioheat transfer}

Both the tissue and blood are heated by absorbing the acoustic energy induced by HIFU, and heat can be transferred between these two compartments if there is a temperature difference. Because of continuous blood circulation, the heated blood at temperature $T_{\mathrm{b}}$ will flow out of the heating region while blood at normal temperature $T_{\mathrm{n}}$ flows in. The corresponding energy conservation equations are summarised in Table 4.

Table 2 Governing equations for interstitial fluid flow

$$
\begin{aligned}
& \text { Continuity equation } \\
& \nabla \cdot \boldsymbol{v}=F_{\mathrm{v}}-F_{\mathrm{ly}} \\
& F_{\mathrm{v}}=K_{\mathrm{v}} \frac{S}{V}\left[p_{\mathrm{v}}-p_{\mathrm{i}}-\sigma\left(\pi_{\mathrm{v}}-\pi_{\mathrm{i}}\right)\right], F_{\mathrm{ly}}=K_{\mathrm{ly}} \frac{S_{\mathrm{ly}}}{V}\left[p_{\mathrm{i}}-p_{\mathrm{ly}}\right] \\
& \text { Momentum equation } \\
& \frac{\partial(\rho \boldsymbol{v})}{\partial t}+\nabla \cdot(\rho \boldsymbol{v} \boldsymbol{v})=-\nabla p_{\mathrm{i}}+\nabla \cdot \tau-\frac{\mu}{\kappa} \boldsymbol{v}
\end{aligned}
$$


Table 3 Acoustic model for high intensity focused ultrasound

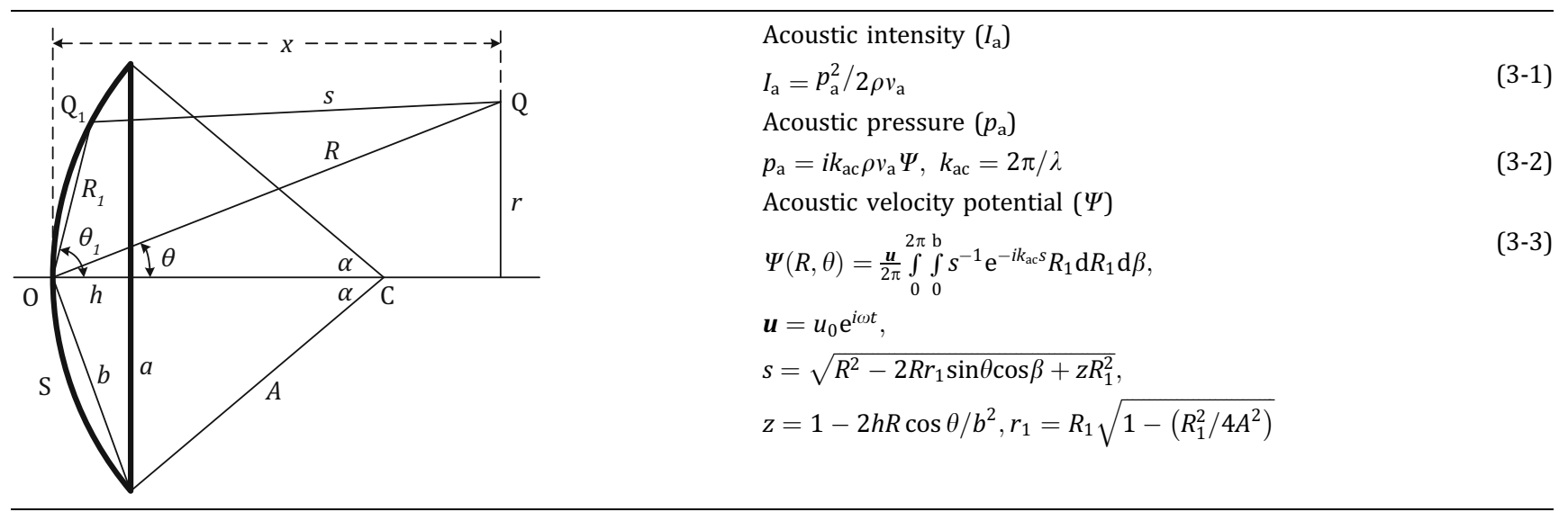

Table 4 Bioheat transfer model
Bioheat transfer in tumour and normal tissue

$\rho_{\mathrm{t}} c_{\mathrm{t}} \frac{\partial T_{\mathrm{t}}}{\partial t}=k_{\mathrm{t}} \nabla^{2} T_{\mathrm{t}}-\rho_{\mathrm{b}} c_{\mathrm{b}} w_{\mathrm{b}}\left(T_{\mathrm{t}}-T_{\mathrm{b}}\right)+2 \alpha_{\mathrm{t}} I_{\mathrm{a}}$

Bioheat transfer in blood

$\rho_{\mathrm{b}} c_{\mathrm{b}} \frac{\partial T_{\mathrm{b}}}{\partial t}=k_{\mathrm{b}} \nabla^{2} T_{\mathrm{b}}+\rho_{\mathrm{b}} c_{\mathrm{b}} w_{\mathrm{b}}\left(T_{\mathrm{t}}-T_{\mathrm{b}}\right)-\rho_{\mathrm{b}} c_{\mathrm{b}} w_{\mathrm{b}}\left(T_{\mathrm{b}}-T_{\mathrm{n}}\right)+2 \alpha_{\mathrm{b}} I_{\mathrm{a}}$
Table 5 Pharmacodynamics model

Pharmacodynamics model

$\frac{\mathrm{d} D_{\mathrm{c}}}{\mathrm{d} t}=-\frac{f_{\max } C_{\mathrm{i}}}{E C_{50}+C_{\mathrm{i}}} D_{\mathrm{c}}+k_{\mathrm{p}} D_{\mathrm{c}}-k_{\mathrm{g}} D_{\mathrm{c}}^{2}$

\section{Drug transport}

Systemic administration is the main delivery method in chemotherapy. Following systemic administration, TSL and chemotherapy drugs (doxorubicin is used here) undergo a series of steps as illustrated in Fig. 12. Briefly, the tumour region consists of three compartments: systemic blood, extracellular space and tumour cells. Within each compartment, letters F, B and L represent free (bioavailable), bound and liposomal doxorubicin, respectively.

Drug transport is determined by drug properties and the in vivo environment after administration. The dynamic process of TSL drug delivery includes triggered drug release from liposomes, association/disassociation of free drugs with proteins, plasma clearance, drug circulation within bloodstream, and exchanges among the circulatory system, extracellular space and tumour cells. The full set of mathematical descriptions is given in Table 1.

\section{Pharmacodynamics model}

Dynamic tumour cell density is determined by drug cytotoxicity, cell proliferation and physiologic degradation, as described in Table 5. In this study, cell proliferation and physiologic degradation are assumed to have reached equilibrium at the start of each treatment.

\section{Model geometry}

The geometry of a prostate tumour is reconstructed from magnetic resonance (MR) images acquired from a patient using a 3.0-Tesla MR scanner (DISCOVERY MR750, GE, Schenectady, New York, USA). Multi-slice anatomical images of the prostate were acquired in three orthogonal planes with echo-planer (EP) sequence, with each image comprising 256 by 256 pixels. In order to build a 2-D model of the tumour and its holding tissue, a representative transverse MR image is selected to cover the maximum tumour dimension, as shown in Fig. 5A. The transverse image is processed using image analysis software MIMICS (Materialise HQ, Leuven, Belgium), and the tumour is segmented from its surrounding normal tissue based on the local signal intensity.

The tumour shown in Fig. 5B is located at the corner of the normal tissue with a dimension of $47 \mathrm{~mm}$ (maximum width) by $38 \mathrm{~mm}$ (maximum depth) in the 
Fig. 12 Drug transport among multiple compartments for thermosensitive liposomemediated drug delivery. L: liposome, F: free drug, B: bound drug

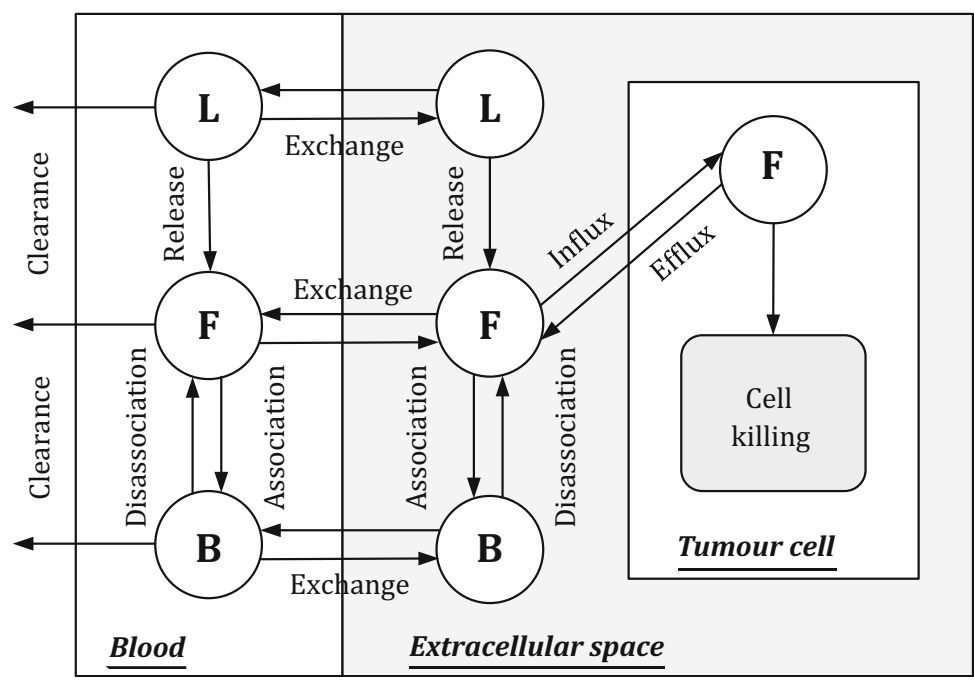

2-D cross-sectional model. Two focus regions are chosen in order to achieve good coverage of the tumour (Mougenot et al. 2009). Both regions are elliptical with major and minor axis radii of $8.7 \mathrm{~mm}$ and $1.5 \mathrm{~mm}$, respectively. ANSYS ICEM CFD (ANSYS Inc., Canonsburg, USA) is used to generate the computational mesh, which consists of 64,966 triangular elements in total. This is obtained based on mesh independence tests which show that differences in predicted acoustic pressure, temperature and drug concentration between the adopted mesh and a 10-times finer mesh are less than $1 \%$.

\section{Model parameters}

Parameters describing the basic physical and transport properties of free, bound and TSL doxorubicin, as well as tumour and normal tissue are summarised in Tables 6, 7, 8 and 9. Justifications for the choices of these parameters have been reported in our previous publications (Zhan et al. 2014a, b). Since temperature elevation in response to HIFU heating may influence several properties used in the drug transport model, temperature dependence of the following transport properties is considered: vascular permeability, diffusivity, transmembrane rate, blood perfusion rate and drug release rate from TSL.

\section{HIFU transducer}

The acoustic source is a single-element, spherically focused transducer, and the geometric parameters are listed in Table 10. The local acoustic intensity and peak negative pressure are set as $120 \mathrm{~W} / \mathrm{cm}^{2}$ and $1.98 \mathrm{MPa}$, respectively.

\section{Temperature controller}

With TSL drug delivery systems, it is desirable to keep the tumour temperature within a narrow hyperthermia range which should not exceed $43{ }^{\circ} \mathrm{C}$ to avoid irreversible tissue damage (Curiel et al. 2004). The phase transition temperature of TSL strongly depends on its formulation, and a typical value for TSL doxorubicin is $42{ }^{\circ} \mathrm{C}$ based on experimental studies (Tagami et al. 2012). In order to achieve the target temperature range, a feedback temperature controller is incorporated, which is designed to adjust the applied ultrasound power according to the maximum temperature in the heated region $\left(T_{\max }\right)$. The transducer power is adjusted according to the controller parameter $P(t)$, which is determined by

$P(t)=k_{\mathrm{cp}}\left[T_{\text {target }}-T_{\max }(t)\right]+k_{\mathrm{ci}} \sum\left[T_{\text {target }}-T_{\max }(t)\right]$,

where $k_{\mathrm{cp}}$ and $k_{\mathrm{ci}}$ are proportional-integral (PI) control parameters, which are set as 5.0 and $6.0 \times 10^{-3}$ respectively, based on values in the literature (Staruch et al. 2011) and our previous studies.

\section{Vascular permeability}

Vascular permeability measures the capacity of a blood vessel (often capillary in tumour) wall to allow for the flow of substances in and out of the vasculature. The structure of vessel wall and the molecular size of the transported substance are key determinants of permeability (Yuan et al. 1995). The logarithmic values of free doxorubicin permeability were found to be proportional to temperature (Dalmark and Storm 1981) as shown in Fig. 13A. The permeability of bound 
Table 6 Biophysical parameters for tumour and normal tissues

\begin{tabular}{|c|c|c|c|c|c|}
\hline Parameter & Definition & Unit & $\begin{array}{l}\text { Tumour } \\
\text { tissue }\end{array}$ & $\begin{array}{l}\text { Normal } \\
\text { tissue }\end{array}$ & References \\
\hline$S / V$ & $\begin{array}{l}\text { Surface area of blood vessels } \\
\text { per unit tissue volume }\end{array}$ & $\mathrm{m}^{-1}$ & $2.0 \times 10^{4}$ & $7.0 \times 10^{3}$ & $\begin{array}{l}\text { (Baxter and Jain 1989, 1990, 1991; } \\
\quad \text { Goh et al. 2001) }\end{array}$ \\
\hline$K_{\mathrm{v}}$ & $\begin{array}{l}\text { Hydraulic conductivity of the } \\
\text { micro-vascular wall }\end{array}$ & $\mathrm{m} /(\mathrm{Pa} \cdot \mathrm{s})$ & $2.10 \times 10^{-11}$ & $2.70 \times 10^{-12}$ & $\begin{array}{l}\text { (Baxter and Jain 1989, 1990, 1991; } \\
\quad \text { Goh et al. 2001) }\end{array}$ \\
\hline$\rho$ & Density of interstitial fluid & $\mathrm{kg} / \mathrm{m}^{3}$ & 1000 & 1000 & (Goh et al. 2001) \\
\hline$\mu$ & $\begin{array}{l}\text { Dynamic viscosity of } \\
\text { interstitial fluid }\end{array}$ & $\mathrm{kg} /(\mathrm{m} \cdot \mathrm{s})$ & $7.8 \times 10^{-4}$ & $7.8 \times 10^{-4}$ & (Goh et al. 2001) \\
\hline $1 / \kappa$ & $\begin{array}{l}\text { Permeability of the interstitial } \\
\text { space }\end{array}$ & $\mathrm{m}^{-2}$ & $4.56 \times 10^{16}$ & $2.21 \times 10^{17}$ & $\begin{array}{l}\text { (Baxter and Jain 1989, 1990, 1991; } \\
\quad \text { Goh et al. 2001) }\end{array}$ \\
\hline$p_{\mathrm{v}}$ & Vascular fluid pressure & $\mathrm{Pa}$ & 2080 & 2080 & $\begin{array}{l}\text { (Baxter and Jain 1989, 1990, 1991; } \\
\quad \text { Goh et al. 2001) }\end{array}$ \\
\hline$\pi_{\mathrm{v}}$ & $\begin{array}{l}\text { Osmotic pressure of the } \\
\text { plasma }\end{array}$ & $\mathrm{Pa}$ & 2666 & 2666 & $\begin{array}{l}\text { (Baxter and Jain 1989, 1990, 1991; } \\
\quad \text { Goh } \text { et al. 2001) }\end{array}$ \\
\hline$\pi_{\mathrm{i}}$ & $\begin{array}{l}\text { Osmotic pressure of } \\
\text { interstitial fluid }\end{array}$ & $\mathrm{Pa}$ & 2000 & 1333 & $\begin{array}{l}\text { (Baxter and Jain 1989, 1990, 1991; } \\
\quad \text { Goh et al. 2001) }\end{array}$ \\
\hline$\sigma_{T}$ & $\begin{array}{l}\text { Average osmotic reflection } \\
\text { coefficient for plasma } \\
\text { proteins }\end{array}$ & & 0.82 & 0.91 & $\begin{array}{l}\text { (Baxter and Jain 1989, 1990, 1991; } \\
\quad \text { Goh et al. 2001) }\end{array}$ \\
\hline$K_{\mathrm{ly}} S_{\mathrm{ly}} / V$ & $\begin{array}{l}\text { Hydraulic conductivity of the } \\
\text { lymphatic wall times } \\
\text { surface area of lymphatic } \\
\text { vessels per unit volume of } \\
\text { tumour tissue }\end{array}$ & $(\mathrm{Pa} \cdot \mathrm{s})^{-1}$ & 0 & $4.17 \times 10^{-7}$ & (Goh et al. 2001) \\
\hline$p_{\text {ly }}$ & Intra-lymphatic pressure & $\mathrm{Pa}$ & 0 & 0 & (Goh et al. 2001) \\
\hline$D_{\mathrm{c}}$ & Cell density & $10^{5} \mathrm{cell} / \mathrm{m}^{3}$ & $1 \times 10^{10}$ & - & (Eikenberry 2009) \\
\hline$V_{\mathrm{T}}$ & Total tumour volume & $\mathrm{m}^{3}$ & $5 \times 10^{-5}$ & $3 \times 10^{-4}$ & (El-Kareh and Secomb 2000) \\
\hline$V_{\mathrm{B}}$ & Total blood volume in body & $\mathrm{m}^{3}$ & $5 \times 10^{-2}$ & $5 \times 10^{-2}$ & (El-Kareh and Secomb 2000) \\
\hline
\end{tabular}

doxorubicin is assumed to follow the same relation. Compared to baseline values at $34^{\circ} \mathrm{C}$, extracellular concentrations of TSL encapsulated doxorubicin increased by 38-fold and 76-fold upon heating to $42{ }^{\circ} \mathrm{C}$ and $45^{\circ} \mathrm{C}$, respectively (Gaber et al. 1996), based on which the relationship between fold increase in TSL permeability and temperature can be obtained as shown in Fig. 13B.

\section{Diffusivity}

According to the Einstein-Stokes equation (Jain 1987b), the fold increase in diffusivity as a function of thermodynamic temperature is

$\frac{D_{1}}{D_{2}}=\frac{T_{1}^{*} \mu_{2}}{T_{2}^{*} \mu_{1}}$,

where $D$ strands for diffusivity, $T^{*}$ is the thermodynamic temperature and $\mu$ is the dynamic viscosity of solvent. Subscripts 1 and 2 correspond to conditions 1 and 2, respectively. Owing to the lack of relevant data, dynamic viscosity values in Eq. 2 are assumed to be those of water (Keenan and Keyes 1936), whose dependence on temperature is given in Fig. 13C.

\section{Transmembrane rate}

The transmembrane parameter is determined by curve fitting to data obtained from in vitro experiments (El-Kareh and Secomb 2000; Kerr et al. 1986). It has been suggested that increased cellular uptake of doxorubicin with heating can lead to improved outcome when the drug is administrated simultaneously with hyperthermia (El-Kareh and Secomb 2000). Based on data in the literature (Nagaoka et al. 1986), there is a 2.2 -fold increase at $42{ }^{\circ} \mathrm{C}$. Here, the fold increase $\left(k_{\mathrm{tv}}\right)$ at temperature $T$ is obtained by linear interpolation as

$k_{\mathrm{tv}}=0.24 T-7.88$. 
Table 7 Transport parameters for doxorubicin

\begin{tabular}{|c|c|c|c|c|c|}
\hline Parameter & Definition & Unit & $\begin{array}{l}\text { Free } \\
\text { doxorubicin }\end{array}$ & $\begin{array}{l}\text { Bound } \\
\text { doxorubicin }\end{array}$ & References \\
\hline$P_{\text {tumour }}$ & $\begin{array}{l}\text { Permeability of } \\
\text { vasculature wall in } \\
\text { tumour }\end{array}$ & $\mathrm{m} / \mathrm{s}$ & $3.00 \times 10^{-6}$ & $7.80 \times 10^{-9}$ & (Goh et al. 2001; Wu et al. 1993b) \\
\hline$P_{\text {normal }}$ & $\begin{array}{l}\text { Permeability of } \\
\text { vasculature wall in } \\
\text { normal tissue }\end{array}$ & $\mathrm{m} / \mathrm{s}$ & $3.75 \times 10^{-7}$ & $2.50 \times 10^{-9}$ & (Goh et al. 2001; Wu et al. 1993b) \\
\hline$D_{\text {tumour }}$ & $\begin{array}{l}\text { Diffusion coefficient in } \\
\text { interstitial fluid of } \\
\text { tumour }\end{array}$ & $\mathrm{m}^{2} / \mathrm{s}$ & $3.40 \times 10^{-10}$ & $8.89 \times 10^{-12}$ & $\begin{array}{l}\text { (Goh et al. 2001; Granath and Kvist 1967; Jain } \\
\text { 1987b; Nugent and Jain 1984; Saltzman and } \\
\text { Radomsky 1991; Swabb et al. 1974) }\end{array}$ \\
\hline$D_{\text {normal }}$ & $\begin{array}{l}\text { Diffusion coefficient in } \\
\text { interstitial fluid of } \\
\text { normal tissue }\end{array}$ & $\mathrm{m}^{2} / \mathrm{s}$ & $1.58 \times 10^{-10}$ & $4.17 \times 10^{-12}$ & $\begin{array}{l}\text { (Goh et al. 2001; Granath and Kvist 1967; Jain } \\
\text { 1987b; Nugent and Jain 1984; Saltzman and } \\
\text { Radomsky 1991; Swabb et al. 1974) }\end{array}$ \\
\hline$\sigma_{d}$ & $\begin{array}{l}\text { Osmotic reflection } \\
\text { coefficient }\end{array}$ & & 0.15 & 0.82 & (Goh et al. 2001; Wolf et al. 1987) \\
\hline$k_{a}$ & $\begin{array}{l}\text { Doxorubicin-protein } \\
\text { binding rate }\end{array}$ & $\mathrm{s}^{-1}$ & 0.833 & - & (Eikenberry 2009) \\
\hline$k_{d}$ & $\begin{array}{l}\text { Doxorubicin-protein } \\
\text { dissociation rate }\end{array}$ & $\mathrm{s}^{-1}$ & - & 0.278 & (Eikenberry 2009) \\
\hline$\varphi$ & $\begin{array}{l}\text { Tumour fraction } \\
\text { extracellular space }\end{array}$ & & 0.4 & & (Eikenberry 2009) \\
\hline$V_{\max }$ & $\begin{array}{l}\text { Rate of } \\
\text { transmembrane } \\
\text { transport }\end{array}$ & $\mathrm{kg} / 10^{5}$ cells & $4.67 \times 10^{-15}$ & - & (Eikenberry 2009; Kerr et al. 1986) \\
\hline$k_{e}$ & $\begin{array}{l}\text { Michaelis constant for } \\
\text { transmembrane } \\
\text { transport }\end{array}$ & $\mathrm{kg} / \mathrm{m}^{3}$ & $2.19 \times 10^{-4}$ & - & $\begin{array}{l}\text { (Eikenberry 2009; El-Kareh and Secomb 2000; Kerr } \\
\text { et al. 1986) }\end{array}$ \\
\hline$k_{i}$ & $\begin{array}{l}\text { Michaelis constant for } \\
\text { transmembrane } \\
\text { transport }\end{array}$ & $\begin{array}{r}\mathrm{kg} / 10^{5} \\
\text { cells }\end{array}$ & $1.37 \times 10^{-12}$ & - & $\begin{array}{l}\text { (Eikenberry 2009; El-Kareh and Secomb 2000; Kerr } \\
\text { et al. 1986) }\end{array}$ \\
\hline$f_{\max }$ & Cell-kill rate constant & $\mathrm{s}^{-1}$ & $1.67 \times 10^{-5}$ & - & (Eliaz et al. 2004) \\
\hline$E C_{50}$ & $\begin{array}{l}\text { Drug concentration } \\
\text { producing } 50 \% \text { of } \\
f_{\max }\end{array}$ & $\begin{array}{r}\mathrm{kg} / 10^{5} \\
\text { cells }\end{array}$ & $5.00 \times 10^{-13}$ & - & (Eliaz et al. 2004) \\
\hline$k_{p}$ & Cell proliferation rate & $\mathrm{s}^{-1}$ & $3.00 \times 10^{-6}$ & - & (Liu et al. 2013) \\
\hline$k_{g}$ & $\begin{array}{l}\text { Cell physiologic } \\
\text { degradation rate }\end{array}$ & $\mathrm{s}^{-1}$ & $3.00 \times 10^{-16}$ & - & (Liu et al. 2013) \\
\hline$C L_{\text {tumour }}$ & $\begin{array}{l}\text { Plasma clearance in } \\
\text { tumour }\end{array}$ & $\mathrm{s}^{-1}$ & $2.43 \times 10^{-3}$ & 0 & $\begin{array}{l}\text { (Benet and Zia-Amirhosseini 1995; Robert et al. } \\
\text { 1982; Rodvold et al. 1988; Solovchuk et al. 2012) }\end{array}$ \\
\hline$C L_{\text {normal }}$ & $\begin{array}{l}\text { Plasma clearance in } \\
\text { normal tissue }\end{array}$ & $\mathrm{s}^{-1}$ & $2.43 \times 10^{-3}$ & 0 & $\begin{array}{l}\text { (Benet and Zia-Amirhosseini 1995; Robert et al. } \\
\text { 1982; Rodvold et al. 1988; Solovchuk et al. 2012) }\end{array}$ \\
\hline
\end{tabular}

Table 8 Transport parameters for liposome

\begin{tabular}{llllll}
\hline Parameter & Definition & Unit & Tumour & Normal tissue & References \\
\hline$P_{1}$ & Liposome permeability of vasculature wall & $\mathrm{m} / \mathrm{s}$ & $3.42 \times 10^{-9}$ & $8.50 \times 10^{-10}$ & (Wu et al. 1993a; Yuan et al. 1994) \\
$D_{\mathrm{l}}$ & Liposome diffusion coefficient & $\mathrm{m}^{2} / \mathrm{s}$ & $9.00 \times 10^{-12}$ & $5.80 \times 10^{-12}$ & (Wu et al. 1993a; Yuan et al. 1995) \\
$\sigma_{\mathrm{l}}$ & Reflection coefficient for liposome & - & 0.95 & 1.0 & (Zhan et al. 2014a) \\
$C L_{\mathrm{lp}}$ & Plasma clearance in tumour & $\mathrm{s}^{-1}$ & $2.23 \times 10^{-4}$ & $2.23 \times 10^{-4}$ & (Gabizon et al. 1994) \\
\hline
\end{tabular}


Table 9 Acoustic and thermal properties

\begin{tabular}{|c|c|c|c|c|c|c|}
\hline \multirow[t]{2}{*}{ Parameter } & \multirow[t]{2}{*}{ Definition } & \multirow[t]{2}{*}{ Unit } & \multicolumn{3}{|l|}{ Value } & \multirow[t]{2}{*}{ References } \\
\hline & & & Blood & Tumour & Normal tissue & \\
\hline$v_{a}$ & Ultrasound speed & $\mathrm{m} / \mathrm{s}$ & 1540 & 1550 & 1550 & (Sheu et al. 2011) \\
\hline$\rho$ & Density & $\mathrm{kg} / \mathrm{m}^{3}$ & 1060 & 1000 & 1055 & (Sheu et al. 2011) \\
\hline$c$ & Specific heat & $\mathrm{J} /(\mathrm{kg} \cdot \mathrm{K})$ & 3770 & 3800 & 3600 & (Sheu et al. 2011) \\
\hline$k$ & Thermal conductivity & $\mathrm{W} /(\mathrm{m} \cdot \mathrm{K})$ & 0.53 & 0.552 & 0.512 & (Sheu et al. 2011) \\
\hline$\alpha$ & Absorption coefficient & - & $1.5 f_{a c}^{*}$ & $9 f_{a c}^{*}$ & $9 f_{a c}^{*}$ & (Sheu et al. 2011) \\
\hline$w_{b o}$ & Blood perfusion rate at $37^{\circ} \mathrm{C}$ & $\mathrm{s}^{-1}$ & - & 0.002 & 0.018 & (Vaupel et al. 1989) \\
\hline$R$ & Universal gas constant & $\mathrm{J} /(\mathrm{mol} \cdot \mathrm{K})$ & - & 8.314 & 8.314 & (Schutt and Haemmerich 2008) \\
\hline$\Delta E$ & Activation energy & $\mathrm{J} / \mathrm{mol}$ & - & $6.67 \times 10^{5}$ & $6.67 \times 10^{5}$ & (Schutt and Haemmerich 2008) \\
\hline$A_{f}$ & Frequency factor & $\mathrm{s}^{-1}$ & - & $1.98 \times 10^{106}$ & $1.98 \times 10^{106}$ & (Schutt and Haemmerich 2008) \\
\hline
\end{tabular}

${ }^{*} f_{a c}$ represents ultrasound frequency

Table 10 HIFU transducer parameters

\begin{tabular}{llll}
\hline Inside diameter $(\mathrm{mm})$ & Outside diameter $(\mathrm{mm})$ & Focal length $(\mathrm{mm})$ & Frequency $(\mathrm{MHz})$ \\
\hline 20.0 & 70.0 & 62.64 & 1.10 \\
\hline
\end{tabular}
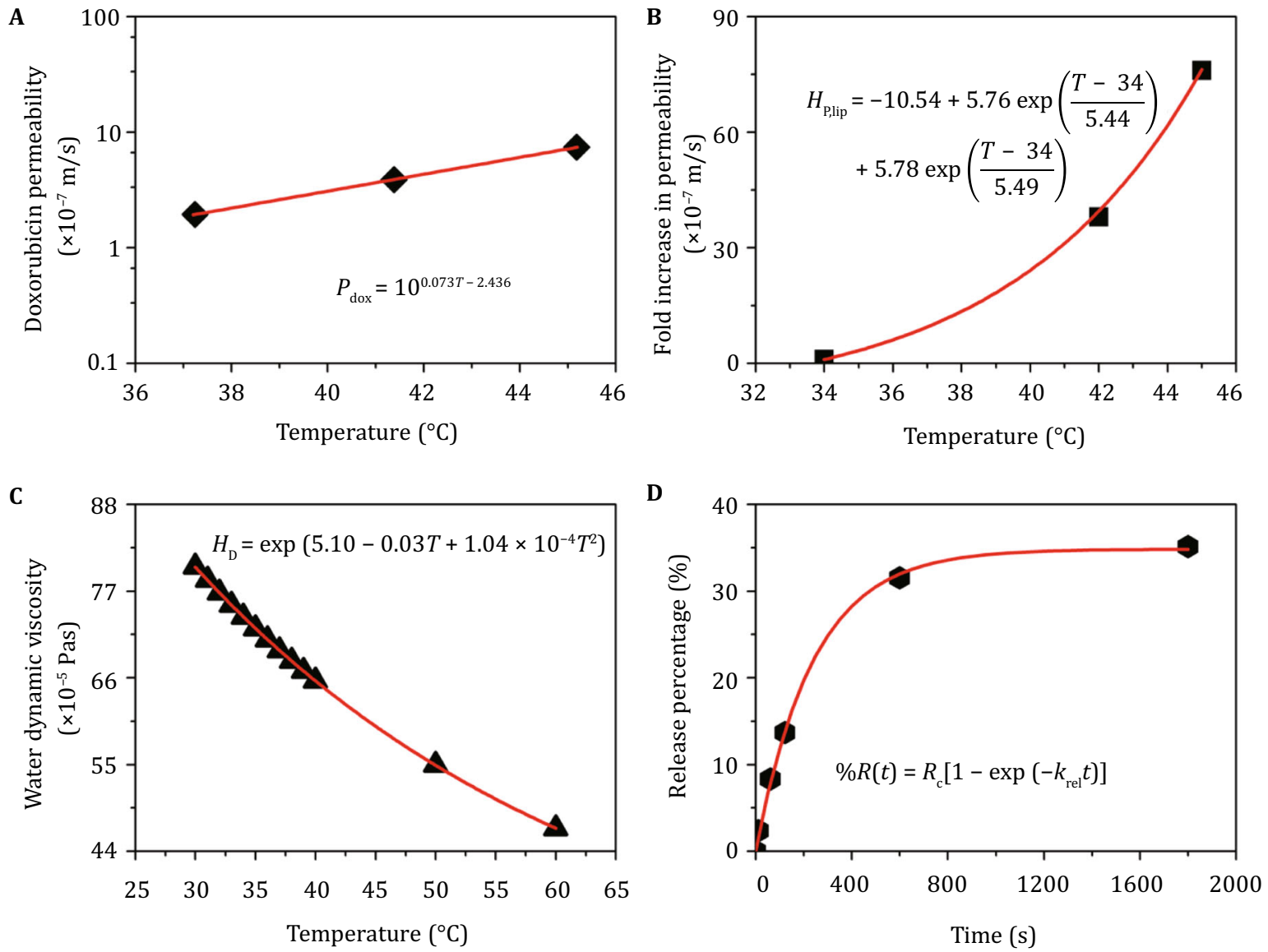

Fig. 13 Derivation of transport parameters from experimental data. A Permeability of free doxorubicin (Dalmark and Storm 1981). B Fold increase in permeability of TSL-loaded doxorubicin (Gaber et al. 1996). C Water dynamic viscosity (Keenan and Keyes 1936). D Drug release rate (Tagami et al. 2012). Experimental data are represented by black dots, and fitting curves are shown in red with the corresponding equations 
Table 11 Release rates at various temperatures

\begin{tabular}{lllllll}
\hline$T\left({ }^{\circ} \mathrm{C}\right)$ & 37.0 & 38.0 & 39.0 & 40.0 & 41.0 & 42.0 \\
\hline$k_{\text {rel }}\left(\mathrm{s}^{-1}\right)$ & $4.17 \times 10^{-3}$ & $5.45 \times 10^{-3}$ & $1.49 \times 10^{-2}$ & $2.82 \times 10^{-2}$ & $4.25 \times 10^{-2}$ & $5.41 \times 10^{-2}$ \\
\hline
\end{tabular}

\section{Blood perfusion rate}

Blood perfusion rate $(w)$ varies with temperature (Schutt and Haemmerich 2008) according to the following relation

$w=w_{0} \exp \left(-\int_{0}^{t} A_{\mathrm{f}} \mathrm{e}^{-\Delta E / R T^{*}(t)} \mathrm{d} \tau\right)$

where $w_{0}$ represents the perfusion rate at $37{ }^{\circ} \mathrm{C}$, and the thermodynamic temperature $T^{*}$ is a function of time $t . R$ is the universal gas constant, and $A_{\mathrm{f}}$ and $\Delta E$ represent the frequency factor and the activation energy, respectively.

\section{Drug release rate from TSL}

TSL is designed to release its payload rapidly upon heating (Zou et al. 1993). The exact release rate varies according to the composition of liposome, its preparation procedure and heating temperature (Tagami et al. 2011). The relation between percentage release and exposure time is found to follow the first-order kinetics expressed as (Afadzi et al. 2010)

$\% R(t)=R_{\mathrm{c}}\left(1-\mathrm{e}^{-k_{\mathrm{rel}} t}\right)$,

where $\% R(t)$ is the percentage of drug released at exposure time $t, R_{\mathrm{c}}$ is the total percentage of drug released at a given heating temperature. This equation is used to fit experimental data (Tagami et al. 2012) and an example for $37^{\circ} \mathrm{C}$ is given in Fig. 13D. Drug release rates at different temperatures in the range of $37-42{ }^{\circ} \mathrm{C}$ are summarised in Table 11.

Note that the TSL formulation used in Tagami et al.'s study (2012) still allows some drugs to be slowly released at $37{ }^{\circ} \mathrm{C}$, although release at $42{ }^{\circ} \mathrm{C}$ is much faster. Linear interpolation is performed to obtain release rate at temperatures between the available temperature points, and the release rate is assumed to be constant if temperature exceeds $42{ }^{\circ} \mathrm{C}$.

\section{Numerical methods}

The mathematical models are implemented into a finitevolume method based computational fluid dynamics code, ANSYS FLUENT (ANSYS Inc., Canonsburg, USA). The user defined scalar function is used to code bioheat transfer model, pharmacokinetics, mass transfer equations for drug transport and pharmacodynamics model. The partial differential equations are spatially discretised by using the 2nd order UPWIND scheme, and the SIMPLEC algorithm is employed for pressure-velocity coupling. The convergence is controlled by setting residual tolerances of the momentum equation, mass transfer equations and bioheat transfer equations to be $1 \times 10^{-5}, 1 \times 10^{-8}$ and $1 \times 10^{-10}$, respectively. Interstitial fluid equations are solved first to obtain a steadystate solution for the entire computational domain. The obtained pressure and velocity fields are adopted as initial values for the simulation of bioheat transfer, drug transport, drug uptake and cell density simultaneously. The 2nd order implicit backward Euler scheme is employed for temporal discretization. A fixed time-step size of $0.1 \mathrm{~s}$ is chosen after time-step sensitivity tests.

\section{Boundary conditions}

For a single chemotherapy treatment, the simulated time window is much shorter than that required for tumour growth. Consequently, all boundaries of the tumour and normal tissue are assumed to be fixed. The interface between the tumour and normal tissue is treated as an internal boundary where all variables are continuous. At the outer surface of normal tissue, a relative pressure of $0 \mathrm{~Pa}$ and temperature of $37^{\circ} \mathrm{C}$ are specified, together with zero flux of drugs.

\section{Compliance with Ethical Standards}

Conflict of interest Wenbo Zhan, Wladyslaw Gedroyc and Xiao Yun Xu declare that they have no conflict of interest.

Human and animal rights and informed consent All imaging data was analysed anonymously and patient information was deidentified prior to this analysis. The anonymized images were saved from the P ACS system by the radiologist who made the image acquisition. Given the archiving of the images for this study was done with an anonymous patient number, the patient could not be identified away from the P ACS system. A prior agreement was made to undertake computational modelling work using totally anonymised images without requiring further specific ethics committee approval for individual patients. Therefore, formal ethical approval was not required for this retrospective study. For this reason, written consent was not obtained from the patient to use the data in this specific study. 
Open Access This article is distributed under the terms of the Creative Commons Attribution 4.0 International License (http:// creativecommons.org/licenses/by/4.0/), which permits unrestricted use, distribution, and reproduction in any medium, provided you give appropriate credit to the original author(s) and the source, provide a link to the Creative Commons license, and indicate if changes were made.

\section{References}

Afadzi M, de L Davies C, Hansen YH, Johansen TF, Standal O-V, Masoy S-E, Angelsen B (2010) Ultrasound stimulated release of liposomal calcein. In: Ultrasonics symposium (IUS), 2010 IEEE. IEEE, 2107-2110

Baxter LT, Jain RK (1989) Transport of fluid and macromolecules in tumors. I. Role of interstitial pressure and convection. Microvasc Res 37:77-104

Baxter LT, Jain RK (1990) Transport of fluid and macromolecules in tumors. II. Role of heterogeneous perfusion and lymphatics. Microvasc Res 40:246-263

Baxter LT, Jain RK (1991) Transport of fluid and macromolecules in tumors. III. Role of binding and metabolism. Microvasc Res 41:5-23

Benet LZ, Zia-Amirhosseini P (1995) Basic principles of pharmacokinetics. Toxicol Pathol 23:115-123

Bhandari A, Bansal A, Singh A, Sinha N (2017) Transport of liposome encapsulated drugs in voxelized computational model of human brain tumors. IEEE Trans Nanobiosci 16:634-644

Curiel L, Chavrier F, Gignoux B, Pichardo S, Chesnais S, Chapelon J (2004) Experimental evaluation of lesion prediction modelling in the presence of cavitation bubbles: intended for high-intensity focused ultrasound prostate treatment. Med Biol Eng Comput 42:44-54

Cusack BJ, Young SP, Driskell J, Olson RD (1993) Doxorubicin and doxorubicinol pharmacokinetics and tissue concentrations following bolus injection and continuous infusion of doxorubicin in the rabbit. Cancer Chemother Pharmacol 32:53-58

Dalmark M, Storm HH (1981) A Fickian diffusion transport process with features of transport catalysis. Doxorubicin transport in human red blood cells. J Gen Physiol 78:349-364

Eikenberry S (2009) A tumor cord model for doxorubicin delivery and dose optimization in solid tumors. Theor Biol Med Model 6:16-36

Eliaz RE, Nir S, Marty C, Szoka FC (2004) Determination and modeling of kinetics of cancer cell killing by doxorubicin and doxorubicin encapsulated in targeted liposomes. Cancer Res 64:711-718

El-Kareh AW, Secomb TW (2000) A mathematical model for comparison of bolus injection, continuous infusion, and liposomal delivery of doxorubicin to tumor cells. Neoplasia 2:325-338

El-Kareh AW, Secomb TW (2003) A mathematical model for cisplatin cellular pharmacodynamics. Neoplasia 5:161-169

Gaber MH, Hong K, Huang SK, Papahadjopoulos D (1995) Thermosensitive sterically stabilized liposomes: formulation and in vitro studies on mechanism of doxorubicin release by bovine serum and human plasma. Pharm Res 12:1407-1416

Gaber MH, Wu NZ, Hong K, Huang SK, Dewhirst MW, Papahadjopoulos D (1996) Thermosensitive liposomes: extravasation and release of contents in tumor microvascular networks. Int J Radiat Oncol Biol Phys 36:1177-1187
Gabizon A, Catane R, Uziely B, Kaufman B, Safra T, Cohen R, Martin F, Huang A, Barenholz Y (1994) Prolonged circulation time and enhanced accumulation in malignant exudates of doxorubicin encapsulated in polyethylene-glycol coated liposomes. Cancer Res 54:987-992

Gasselhuber A, Dreher MR, Rattay F, Wood BJ, Haemmerich D (2012a) Comparison of conventional chemotherapy, stealth liposomes and temperature-sensitive liposomes in a mathematical model. PLoS One 7:e47453

Gasselhuber A, Dreher MR, Partanen A, Yarmolenko PS, Woods D, Wood BJ, Haemmerich D (2012b) Targeted drug delivery by high intensity focused ultrasound mediated hyperthermia combined with temperature-sensitive liposomes: computational modelling and preliminary in vivo validation. Int $\mathrm{J}$ Hyperth 28:337-348

Goh YM, Kong HL, Wang CH (2001) Simulation of the delivery of doxorubicin to hepatoma. Pharm Res 18:761-770

Granath KA, Kvist BE (1967) Molecular weight distribution analysis by gel chromatography on Sephadex. J Chromatogr A 28:69-81

Grüll H, Langereis S (2012) Hyperthermia-triggered drug delivery from temperature-sensitive liposomes using MRI-guided high intensity focused ultrasound. J Controll Release 161:317-327

Hossann M, Wang T, Wiggenhorn M, Schmidt R, Zengerle A, Winter G, Eibl H, Peller M, Reiser M, Issels RD, Lindner LH (2010) Size of thermosensitive liposomes influences content release. J Controll Release 147:436-443

Hynynen K (2011) MRIgHIFU: a tool for image-guided therapeutics. J Magn Reson Imaging 34:482-493

Jain RK (1987a) Transport of molecules across tumor vasculature. Cancer Metastasis Rev 6:559-593

Jain RK (1987b) Transport of molecules in the tumor interstitium: a review. Cancer Res 47:3039-3051

Keenan JH, Keyes FG (1936) Thermodynamic properties of steam: including data for the liquid and solid phases. Wiley, New York

Kerr DJ, Kerr AM, Freshney RI, Kaye SB (1986) Comparative intracellular uptake of adriamycin and 4'-deoxydoxorubicin by non-small cell lung tumor cells in culture and its relationship to cell survival. Biochem Pharmacol 35:2817-2823

Legha SS, Benjamin RS, Mackay B, Ewer M, Wallace S, Valdivieso M, Rasmussen SL, Blumenschein GR, Freireich EJ (1982) Reduction of doxorubicin cardiotoxicity by prolonged continuous intravenous infusion. Ann Intern Med 96:133-139

Lindner LH, Eichhorn ME, Eibl H, Teichert N, Schmitt-Sody M, Issels RD, Dellian M (2004) Novel temperature-sensitive liposomes with prolonged circulation time. Clin Cancer Res 10:2168-2178

Liu C, Xu XY (2015) A systematic study of temperature sensitive liposomal delivery of doxorubicin using a mathematical model. Comput Biol Med 60:107-116

Liu C, Krishnan J, Xu XY (2013) Investigating the effects of ABC transporter-based acquired drug resistance mechanisms at the cellular and tissue scale. Integr Biol 5:555-568

Luu KT, Uchizono JA (2005) P-glycoprotein induction and tumor cell-kill dynamics in response to differential doxorubicin dosing strategies: a theoretical pharmacodynamic model. Pharm Res 22:710-715

Lyon PC, Gray MD, Mannaris C, Folkes LK, Stratford M, Campo L, Chung DYF, Scott S, Anderson M, Goldin R, Carlisle R, Wu F, Middleton MR, Gleeson FV, Coussios CC (2018) Safety and feasibility of ultrasound-triggered targeted drug delivery of doxorubicin from thermosensitive liposomes in liver tumours (TARDOX): a single-centre, open-label, phase 1 trial. Lancet Oncol 19:1027-1039 
Mougenot C, Quesson B, de Senneville BD, de Oliveira PL, Sprinkhuizen S, Palussière J, Grenier N, Moonen CT (2009) Three-dimensional spatial and temporal temperature control with MR thermometry-guided focused ultrasound (MRgHIFU). Magn Reson Med 61:603-614

Nagaoka S, Kawasaki S, Sasaki K, Nakanishi T (1986) Intracellular uptake, retention and cytotoxic effect of adriamycin combined with hyperthermia in vitro. Jpn J Cancer Res 77:205-211

Nugent LJ, Jain RK (1984) Extravascular diffusion in normal and neoplastic tissues. Cancer Res 44:238-244

O'Neil H (1949) Theory of focusing radiators. J Acoust Soc Am 21:516-526

Raghunathan S, Evans D, Sparks JL (2010) Poroviscoelastic modeling of liver biomechanical response in unconfined compression. Ann Biomed Eng 38:1789-1800

Robert J, Illiadis A, Hoerni B, Cano J-P, Durand M, Lagarde C (1982) Pharmacokinetics of adriamycin in patients with breast cancer: correlation between pharmacokinetic parameters and clinical short-term response. Eur J Cancer Clin Oncol 18:739-745

Rodvold KA, Rushing DA, Tewksbury DA (1988) Doxorubicin clearance in the obese. J Clin Oncol 6:1321-1327

Saltzman WM, Radomsky ML (1991) Drugs released from polymers: diffusion and elimination in brain tissue. Chem Eng Sci 46:2429-2444

Schutt DJ, Haemmerich D (2008) Effects of variation in perfusion rates and of perfusion models in computational models of radio frequency tumor ablation. Med Phys 35:3462-3470

Sheu TWH, Solovchuk MA, Chen AWJ, Thiriet M (2011) On an acoustics-thermal-fluid coupling model for the prediction of temperature elevation in liver tumor. Int J Heat Mass Transf 54:4117-4126

Solovchuk MA, Sheu TW, Lin W-L, Kuo I, Thiriet M (2012) Simulation study on acoustic streaming and convective cooling in blood vessels during a high-intensity focused ultrasound thermal ablation. Int J Heat Mass Transf 55:1261-1270

Staruch R, Chopra R, Hynynen K (2011) Localised drug release using MRI-controlled focused ultrasound hyperthermia. Int J Hyperth 27:156-171

Swabb EA, Wei J, Gullino PM (1974) Diffusion and convection in normal and neoplastic tissues. Cancer Res 34:2814-2822

Tagami T, Ernsting MJ, Li SD (2011) Optimization of a novel and improved thermosensitive liposome formulated with DPPC and a Brij surfactant using a robust in vitro system. J Controll Release 154:290-297

Tagami T, May JP, Ernsting MJ, Li S-D (2012) A thermosensitive liposome prepared with a $\mathrm{Cu}^{2+}$ gradient demonstrates improved pharmacokinetics, drug delivery and antitumor efficacy. J Controll Release 161:142-149

Teo CS, Hor Keong Tan W, Lee T, Wang C-H (2005) Transient interstitial fluid flow in brain tumors: effect on drug delivery. Chem Eng Sci 60:4803-4821

Vaupel P, Kallinowski F, Okunieff P (1989) Blood flow, oxygen and nutrient supply, and metabolic microenvironment of human tumors: a review. Cancer Res 49:6449-6465

Wolf MB, Watson PD, Scott DR 2nd (1987) Integral-mass balance method for determination of solvent drag reflection coefficient. Am J Physiol 253:H194-H204

Wu NZ, Da D, Rudoll TL, Needham D, Whorton AR, Dewhirst MW (1993a) Increased microvascular permeability contributes to preferential accumulation of stealth liposomes in tumor tissue. Cancer Res 53:3765-3770

Wu NZ, Klitzman B, Rosner G, Needham D, Dewhirst MW (1993b) Measurement of material extravasation in microvascular networks using fluorescence video-microscopy. Microvasc Res 46:231-253

Yuan F, Leunig M, Huang SK, Berk DA, Papahadjopoulos D, Jain RK (1994) Microvascular permeability and interstitial penetration of sterically stabilized (stealth) liposomes in a human tumor xenograft. Cancer Res 54:3352-3356

Yuan F, Dellian M, Fukumura D, Leunig M, Berk DA, Torchilin VP, Jain RK (1995) Vascular permeability in a human tumor xenograft: molecular size dependence and cutoff size. Cancer Res 55:3752-3756

Zhan W, Wang C-H (2018) Convection enhanced delivery of liposome encapsulated doxorubicin for brain tumour therapy. J Controll Release 285:212-229

Zhan W, Gedroyc W, Xu XY (2014a) Effect of heterogeneous microvasculature distribution on drug delivery to solid tumour. J Phys D 47:475401

Zhan W, Gedroyc W, Yun XuX (2014b) Mathematical modelling of drug transport and uptake in a realistic model of solid tumour. Protein Pept Lett 21:1146-1156

Zhang A, Mi X, Yang G, Xu LX (2009) Numerical study of thermally targeted liposomal drug delivery in tumor. J Heat Transf 131:043209

Zhao J, Salmon H, Sarntinoranont M (2007) Effect of heterogeneous vasculature on interstitial transport within a solid tumor. Microvasc Res 73:224-236

Zou Y, Yamagishi M, Horikoshi I, Ueno M, Gu X, Perez-Soler R (1993) Enhanced therapeutic effect against liver W256 carcinosarcoma with temperature-sensitive liposomal adriamycin administered into the hepatic artery. Cancer Res 53:3046-3051 